\title{
Workplace-related stress among oncologists: Egyptian single-centered observational study
}

\author{
M. R. Soltan ${ }^{1 *}$, S. A. Al-Hassanin², S. S. Soliman³ and S. F. Gohar²
}

\begin{abstract}
Background: The oncologists are facing more challenges than ever before in their work with cancer patients. The aim of the study is to assess the level of work-related stress among oncology clinicians and to compare it with non-oncologists. Thirty oncologists working at clinical oncology department at Menoufia University hospitals, Egypt, were compared to an equal number of non-oncologists matched for the same gender and work duration. After consent, all the participants were interviewed using a structured questionnaire to collect background information and the workplace stress scale (WSS) was used to ascertain their stress level.

Results: The percentage distribution of different grades of WSS among the two groups did not show any significant difference $(P=0.84)$. Gender had no significant association to the mean score of WSS $(P>0.05)$. All the juniors (residents) in this study with work duration $\leq 3$ years had significantly higher levels of WSS than seniors ( $>3$ years), $P<0.001$. Among oncologists or non-oncologists, juniors showed significantly higher levels of WSS than seniors ( $P=0.003$ and $<0.001$ respectively). However, junior oncologists had no significant difference than junior non-oncologists and seniors in both groups did not show any significant difference regarding the mean score of WSS.
\end{abstract}

Conclusion: All the workers within the two groups had experienced work-related stress. However, there was no statistically significant difference among them regarding the different grades of work place stress scale.

Keywords: Workplace, Stress, Oncologists

\section{Background}

According to WHO definition, occupational or workrelated stress is "the response people may have when presented with work demands and pressures that are not matched to their knowledge and abilities and which challenge their ability to cope" [1].

Certain factors in work that occur over a prolonged time cause stress to all people. Work demands may be related to time pressure or the amount of work (quantitative demands); they also may refer to the difficulty of the work (cognitive demands) or the empathy required (emotional

\footnotetext{
*Correspondence: Dr.mohamedsoltan1979@gmail.com

'Department of Psychiatry, Faculty of medicine, Fayoum University, PO Box: 63514, Fayoum, Egypt

Full list of author information is available at the end of the article
}

demands) or even to the inability to show one's emotions at work. Demands may be physical, that is, high demands in the area of dynamic and static loads [2-5].

Ongoing changes in cancer care cause an increase in the complexity of cases which is characterized by modern treatment techniques and a higher demand for patient information about the underlying disease and therapeutic options. At the same time, the restructuring of health services and reduced funding have led to the downsizing of hospital care services. These trends strongly influence the workplace environment and are a potential source of stress and burnout among professionals working in oncology [6].

The prevalence of cancer diagnoses increases the likelihood that healthcare professionals will be presented

\section{Springer Open}

(c) The Author(s). 2020 Open Access This article is licensed under a Creative Commons Attribution 4.0 International License, which permits use, sharing, adaptation, distribution and reproduction in any medium or format, as long as you give appropriate credit to the original author(s) and the source, provide a link to the Creative Commons licence, and indicate if changes were made. The images or other third party material in this article are included in the article's Creative Commons licence, unless indicated otherwise in a credit line to the material. If material is not included in the article's Creative Commons licence and your intended use is not permitted by statutory regulation or exceeds the permitted use, you will need to obtain permission directly from the copyright holder. To view a copy of this licence, visit http://creativecommons.org/licenses/by/4.0/. 
with individuals struggling with cancer. Hospitals manage, monitor, and treat the sickest cancer patients and continue to observe steady increases in acuity, turnover, and even death. The rise in cancer cases also means that oncology healthcare professionals are faced with increased daily challenges to ease the emotional burdens of cancer patients, intervene in new and creative ways with shrinking resources, and to demonstrate the efficacy of their work with clients [7].

Numerous investigations have been attempted to document the impact of work activities on the mental health of cancer specialists. Work stress, if prolonged and intensified, can result in chronic reactions and lead professionals to negative affective states [8].

The objective of this study was to assess the level of workplace-related stress among oncology clinicians and to compare it with non-oncologists.

\section{Methods}

It is a cross-sectional observational study conducted at Menoufia University Hospitals, between September and December 2016. A total of 30 physicians (group I) working in the Oncology Department at Menoufia University Hospitals were included and an equal number of nononcologists (group II) (including general surgery, internal medicine, chest, cardiology, neurology, neurosurgery, cardiothoracic, emergency medicine, intensive care, gynecology and obstetrics, pediatrics, and tropical medicine) were matched for the same gender and work duration (juniors $\leq 3$ years or seniors $>3$ years).

The approval of the Institute's ethics committee was obtained prior to the study. Confidentiality of the subjects was maintained. Informed consent from the respondents was obtained for data collection and publication of research findings.

The participants were interviewed using a structured questionnaire to collect background information and the workplace stress scale (WSS) to ascertain their stress level [9].

The workplace stress scale (WSS) was developed by the Marlin Company, North Haven, CT, USA, and the American Institute of Stress, Yonkers, NY, USA (2001). The WSS consists of eight items describing how often a respondent feels toward his or her job. Examples of items in the scale include "Conditions at work are unpleasant or sometimes even unsafe" and "I feel that my job is negatively affecting my physical or emotional wellbeing." In terms of scoring, item numbers 6,7 , and 8 are reverse-scored. The scale is in the five-point Likert response format, ranging from never (scored 1) to very often (scored 5). High scores are indicative of higher levels of job stress. Respondents' total scores are interpreted as follows: scores of 15 and below: relatively calm, 16-20: fairly low, 21-25: moderate levels of work stress,
26-30: severe levels of work stress, and 31-40: potentially dangerous level of work stress. We assessed the validity of the scale by seeking opinions of oncology nurses as experts. Their suggestions were discussed by the authors and considered in the modification of test items where necessary. In the current study, we reported a Cronbach's alpha reliability coefficient of 0.80 for the entire scale WSS.

The authors compared between the two groups regarding age, gender, work duration, and workplace stress scale grade, which was then analyzed to assess the variations in stress response.

Statistical analysis : data were presented as numbers (No.), percentages (\%), means and Standard deviations (SD) and were analyzed by SPSS statistical package version 23 (SPSS Inc. Released 2015. IBM SPSS statistics for windows, version 23.0, Armnok, NY: IBM Corp.). Student's $t$-test is a test of significance used for comparison of quantitative variables between two groups of normally distributed data. while Mann Whitney's test was used for comparison of quantitative variables between two groups of not normally distributed data. Chi-square test $\left(x^{2}\right)$ was used to study association between qualitative variables. Whenever any of the expected cells were less than five, Fischer's Exact test was used. Analysis of the variance (ANOVA) test was used for comparison of quantitative variables between more than two groups of normally distributed data with Tuckey test as post Hoc test.

\section{Results}

The studied groups were matched for age, gender, and work duration as shown in Table 1. There was no statistically significant difference between the two groups as regarding age, work duration (in years), gender, numbers of night shifts per week, and categories of work duration $(\leq 3$ or $>3$ years $)(P>0.05)$. However, oncologists had more night shifts per week than other group as 43.3\% $(N=13)$ oncologists vs. $33.3 \%(N=10)$ of nononcologists working 5-6 nights per week.

The percentage distribution of different grades of WSS among the two groups did not show any significant difference $(P=0.84)$. Among oncologists, $16.7 \%$ had fairly low stress, $36.7 \%$ moderate stress, $40 \%$ severe, and $6.7 \%$ had dangerous levels of stress. Among non-oncologists, $3.3 \%$ had chilled out, $16.7 \%$ fairly low, 33.3\% moderate, $43.3 \%$ severe, and only $3.3 \%$ had dangerous level of stress. This is shown in Table 2.

Gender had no significant association to the mean score of WSS $(P>0.05)$. All the juniors (residents) in this study with work duration $\leq 3$ years had significantly higher levels of WSS than seniors ( $>3$ years) $(P<0.001)$. Also, participants who had 5-6 night shifts/w showed the highest stress level followed by those who had 3-4 night shifts/w and lastly participants who had 0-2 night 
Table 1 Descriptive statistics of the studied groups

\begin{tabular}{|c|c|c|c|c|}
\hline & $\begin{array}{l}\text { Oncologist }(n=30) \\
\text { mean } \pm \text { SD }\end{array}$ & $\begin{array}{l}\text { Non-oncologist } \\
(n=30) \text { mean } \pm \mathrm{SD}\end{array}$ & Test of sig & $\begin{array}{l}P \\
\text { value }\end{array}$ \\
\hline Age & $30.14 \pm 5.43$ & $28.70 \pm 3.47$ & $t=1.2$ & 0.22 \\
\hline \multirow{2}{*}{$\begin{array}{l}\text { Work } \\
\text { duration }\end{array}$} & $4.86 \pm 4.84$ & $4.13 \pm 2.87$ & $U=0.70$ & 0.84 \\
\hline & No. (\%) & No. (\%) & $\Sigma^{2}$ & $\begin{array}{l}P \\
\text { value }\end{array}$ \\
\hline \multicolumn{5}{|l|}{ Gender } \\
\hline Male & $19(63.3)$ & 17 (56.7) & 0.27 & 0.59 \\
\hline Female & $11(36.7)$ & $13(43.3)$ & & \\
\hline \multicolumn{5}{|c|}{ Night shifts/w } \\
\hline $5-6$ & $13(43.3)$ & 10 (33.3) & 1.08 & 0.58 \\
\hline $3-4$ & $12(40.0)$ & $12(40.0)$ & & \\
\hline $0-2$ & $5(16.7)$ & $8(26.7)$ & & \\
\hline \multicolumn{5}{|l|}{$\begin{array}{l}\text { Work } \\
\text { duration }\end{array}$} \\
\hline $\begin{array}{l}\leq 3 \\
\text { years }\end{array}$ & $17(56.7)$ & $17(56.7)$ & 0.00 & 1.00 \\
\hline $\begin{array}{l}>3 \\
\text { years }\end{array}$ & $13(43.3)$ & $13(43.3)$ & & \\
\hline
\end{tabular}

shifts/w who had the lowest stress level with significant difference among them as shown in Table 3.

Among oncologists or non-oncologists, juniors showed significantly higher levels of WSS than seniors $(P=$ 0.003 and $<0.001$ respectively). However, junior oncologists had no significant difference than junior nononcologists and seniors in both groups did not show any significant difference regarding the mean score of WSS. This is shown in Table 4.

The WSS questionnaire included 8 items about work environment and other work-related stressors. There was no significant difference among the two groups regarding different items of the questionnaire $(P>0.05)$. Eightyseven percent of oncologists sometimes, or even rarely felt appreciated, rewarded for their work and $76.7 \%$ of oncologists sometimes, or even rarely utilized their skills and

Table 2 Distribution of workplace stress scale grades in the groups

Oncologist non-oncologist Fisher's exact $P$ value $(n=30)$ no. (\%) $(n=30)$ no. $(\%)$ test

\begin{tabular}{lllll}
\hline $\begin{array}{l}\text { Scale grades } \\
\begin{array}{l}\text { Chilled } \\
\text { out }\end{array}\end{array}$ & $0(0.0)$ & $1(3.3)$ & 1.42 & 0.84 \\
Fairly low & $5(16.7)$ & $5(16.7)$ & & \\
Moderate & $11(36.7)$ & $10(33.3)$ & \\
Severe & $12(40.0)$ & $13(43.3)$ & \\
Dangerous & $2(6.7)$ & $1(3.3)$ & \\
\hline
\end{tabular}

Table 3 Comparison of the mean score of Work Place Stress Scale according to all other parameters

\begin{tabular}{|c|c|c|c|c|}
\hline & Score & Test of sig. & $P$ value & $\begin{array}{l}\text { Pairwise } \\
\text { comparison }\end{array}$ \\
\hline \multicolumn{5}{|l|}{ Gender: } \\
\hline Male $(n=36)$ & $24.58 \pm 4.45$ & $t=0.63$ & 0.52 & - \\
\hline Female: $(n=24)$ & $25.33 \pm 4.54$ & & & \\
\hline \multicolumn{5}{|l|}{ Work duration: } \\
\hline$\leq 3$ year $(n=34)$ & $27.35 \pm 3.74$ & $t=6.29$ & $<0.001$ & - \\
\hline$>3$ year $(n=26)$ & $21.65 \pm 3.08$ & & & \\
\hline \multicolumn{5}{|l|}{$\begin{array}{l}\text { Number of night } \\
\text { shifts: }\end{array}$} \\
\hline $5-6 / w(n=23)$ & $27.95 \pm 3.61$ & ANOVA $=18.02$ & $<0.001$ & P1 0.001 \\
\hline $3-4 / w(n=24)$ & $24.20 \pm 3.82$ & & & $\mathrm{P} 2<0.001$ \\
\hline $0-2 / w(n=13)$ & $20.69 \pm 2.86$ & & & P3 0.006 \\
\hline
\end{tabular}

P1 for comparison between those who have 5-6night shifts /w and those who have 3-4night shifts /w

P2 for comparison between those who have 5-6night shifts / $w$ and those who have $0-2$ night shifts $/ \mathrm{w}$

P3 for comparison between those who have 3-4 night shifts / $w$ and those who have $0-2$ night shifts /w

talents to the fullest extent at work than non-oncologists (76.7\%) (30\%) respectively. Also, $46.7 \%$ of oncologists often or very often had too much work to do and/or too many unreasonable deadlines than non-oncologists (30\%) with no statistically significant difference.

However, $55.2 \%$ of non-oncologists only sometimes or even had adequate control or input over work duties than oncologists $(33.3 \%)$ with no statistically significant difference. Also, non-oncologists often or very often had job pressures that interfere with family or personal life (46.7\%), unpleasant or unsafe workplace (40\%), negative affection of job on physical or emotional well-being

Table 4 Comparison between either juniors or seniors (oncologists or physician non-oncologist) and the mean score of Work Place Stress Scale

\begin{tabular}{llll}
\hline & Score & Test of sig. & $P$ value \\
\hline $\begin{array}{llll}\text { Oncologists } \\
\text { Juniors }(n=17)\end{array}$ & $27.17 \pm 4.88$ & $t=3.24$ & 0.003 \\
Seniors $(n=13)$ & $22.0 \pm 3.46$ & & \\
Non oncologist & & & \\
$\quad$ Juniors $(n=17)$ & $27.52 \pm 2.21$ & $t=6.87$ & $<0.001$ \\
Seniors $(n=13)$ & $21.30 \pm 2.75$ & & \\
& Score & & \\
Juniors & & & \\
Oncologists $(n=17)$ & $27.17 \pm 4.88$ & $t=0.27$ & 0.78 \\
Non-oncologists $(n=17)$ & $27.52 \pm 2.21$ & & \\
Seniors & & & \\
Oncologists $(n=13)$ & $22.0 \pm 3.46$ & $t=0.56$ & \\
Non-oncologists $(n=13)$ & $21.30 \pm 2.75$ & & \\
\hline
\end{tabular}


(40\%), and difficulty to express opinions or feelings about job conditions to seniors (33.3\%) than oncologists (43.3\%) (33.4\%) (36.6\%) (30\%) respectively with no statistically significant difference, as shown in Table 5.

\section{Discussion}

According to Sehlen et al. [6], most of the physicians showed the highest level of job stress. Oncologists are exposed to many stressors including the type of patient, nature of the disease, work duration, and unpleasant work environment. However, in this study, $33.4 \%$ of oncologists and $40 \%$ of non-oncologists rated themselves as "often or very often" having an "unpleasant or unsafe workplace." So, oncologists are not alone in having an "unpleasant work environment."

In this study, there was no significant difference in the stress levels between oncologists and physicians of other specialties. This was consistent with a cross-sectional survey that was conducted by Berman et al. [10] to compare stress levels between specialist registrars in palliative medicine, clinical oncology, and medical oncology and showed that there were no significant differences between specialties.

Moreover, research comparing oncologists with other specialists in the UK has not found any differences in levels of burnout or psychiatric morbidity. Why might this be? The answer seems to lie in factors that are actually generic to the role of doctor. In fact, oncologists report work overload, poor management and resourcing, and dealing with patient suffering to be predominant sources of stress [11]. Furthermore, compared to other specialist groups with clinical responsibility for patients, oncologists do not report higher stress from dealing with patient suffering and do not, therefore, appear to experience uniquely high levels of stress from this aspect of work [12].

Forty percent of oncologists in this work had severe stress, $36.7 \%$ had moderate stress, $16.7 \%$ had fairly low stress, and $6.7 \%$ had dangerous stress levels. Among physicians of other specialties, $43.3 \%$ had severe stress, $33.3 \%$ had moderate stress, $16.7 \%$ had fairly low stress, and $3.3 \%$ had dangerous stress. These results were consistent with Firth-Cozenset al [13]. who found that the proportion of doctors and other health professionals showing above threshold levels of stress at around $28 \%$.

Among oncologists or physicians of other specialties, juniors showed significantly higher levels of WSS than seniors $(P=0.003$ and $<0.001$ respectively) which may be related to low autonomy, work overload, limited time, low experience, over sympathizing with patients, and lack of congruence between power and responsibility. This was also consistent with other studies in different parts of the world. For example, Schindler et al. [14] in USA, Ahsan et al. [15] in Malaysia, Ghazaliet al [16]. in Pakistan, and Aniediet al [17]. in Nigeria who found that elevated stress levels in junior doctors have been widely reported.

Also, the present study confirmed the results of other studies showing more job stress among younger oncologists [18-23]. This effect may arise from multiple factors with significantly higher stress levels for younger oncologists in structural conditions, compassion, professional and private life, and problems with colleagues [24]. These 4 issues seem to be the central problems for younger oncologists, independent of their specialization.

The current study showed a statistically significant association between the number of night shifts within physicians (either oncologists or non-oncologists) and the mean score of WSS $(P<0.001)$ with higher scores among physicians receiving more night shifts/w. Data supports the notion that night time work is hazardous to a person's long-term well-being like Arkerstedt et al. [25] who found that oncologists reported more job distress when they were working night shifts, and weekends or were not getting free time compensation for working long hours.

In the present study, among oncologists, not feeling appreciated or rewarded for work, too much work to do and/ or too many unreasonable deadlines, and no utilization of their skills and talents to the fullest extent at work were the most prevalent stressors. These parameters were more evident among oncologists than non-oncologists but with no statistically significant difference between both groups. However, among physician non-oncologists, having inadequate control or input over work duties, job pressures that interfere with family or personal life, negative affection of job on physical or emotional well-being, having unpleasant or unsafe workplace, and difficulty to express opinions or feelings about job conditions to superiors were the most prevalent stressors among physicians of other specialties than oncologists with no statistically significant difference.

This was consistent with Vedat et al. [26], who studied factors influencing stress in healthcare professionals working with cancer patients and found that variables influencing stress scores were marital status, age, professional career, unfairness in promotion opportunities, imbalance between jobs and responsibilities, conflict with colleagues, lack of appreciation of efforts by seniors, responsibilities of role, long and tiring work hours, inadequacy of equipment, and problems experienced with patients and their relatives. Similarly, Ramirez et al. [27] found work overload, organization responsibilities, and conflicts as source of professional dissatisfaction and burnout in non-surgical oncologists.

This result was in line with the survey of the Spanish Society of Medical Oncology [28], which showed the perception of time pressure and social deterioration to be responsible for high burnout levels. Shanafelt et al. [29] found that, among the North Central Cancer Treatment Group (NCCTG) for medical oncologists, "patient 
Table 5 Comparison between oncologist and non-oncologist regarding different items of work place stress scale

\begin{tabular}{lllll}
\hline Oncologist & Non- & Fisher's & $P$ \\
$(n=30)$ & oncologist & exact & value \\
no. \% & $(n=30)$ no. & test & \\
& $\%$ & & \\
\hline
\end{tabular}

A: unpleasant or unsafe workplace

Rarely
Sometimes
Often
Very often
B. job negatively affecting
physical or emotional well
being

Never

Rarely

Sometimes

Often

Very often

C. too much work to do and/or too many

unreasonable deadlines

Never

Sometimes

Often

Very often

D. difficulty to express opinions or feelings about job conditions to superiors

$\begin{array}{lllll}\text { Never } & 1(3.3) & 2(6.7) & 1.36 & 0.88 \\ \text { Rarely } & 9(30.0) & 10(33.3) & & \\ \text { Sometimes } & 11(36.7) & 8(26.7) & & \\ \text { Often } & 5(16.7) & 7(23.3) & & \\ \text { Very often } & 4(13.3) & 3(10.0) & & \\ \text { E. job pressures interfere } & & & & \\ \text { with family or personal life } & & & & \\ \text { Never } & 3(10.0) & 1(3.3) & 2.53 & \\ \text { Rarely } & 2(6.7) & 5(16.7) & & \\ \text { Sometimes } & 12(40.0) & 10(33.3) & & \\ \text { Often } & 7(23.3) & 8(26.7) & & \\ \text { Very often } & 6(20.0) & 6(20.0) & & \\ \begin{array}{l}\text { F. adequate control or } \\ \text { input over work duties }\end{array} & & & & \\ \text { Rarely } & 5(16.7) & 3(10.3) & 5.52 & 0.14 \\ \text { Sometimes } & 5(16.7) & 13(44.8) & & \\ \text { Often } & 17(56.7) & 11(37.9) & \\ \text { Very often } & 3(10.0) & 2(6.9) & \end{array}$

Table 5 Comparison between oncologist and non-oncologist regarding different items of work place stress scale (Continued)

\begin{tabular}{llll}
\hline Oncologist & Non- & Fisher's & $P$ \\
$(n=30)$ & oncologist & exact & value \\
no. \% & $(n=30)$ no. & test & \\
& $\%$ & & \\
& & &
\end{tabular}

\begin{tabular}{lllll}
\hline $\begin{array}{l}\text { G. appropriate recognition } \\
\text { or rewards for good } \\
\text { performance }\end{array}$ & & & & \\
$\quad$ Never & $4(13.3)$ & $5(16.7)$ & 2.07 & 0.56 \\
Rarely & $8(26.7)$ & $9(30.0)$ & & \\
Sometimes & $14(46.7)$ & $9(30.0)$ & & \\
Often & $4(13.3)$ & $7(23.3)$ & & \\
$\quad$ Very often & $0(0.0)$ & $0(0.0)$ & \\
$\begin{array}{l}\text { H. able to utilize skills and } \\
\text { talents to the fullest extent } \\
\text { at work }\end{array}$ & & & \\
$\quad$ Never & $1(3.3)$ & $1(3.3)$ & 7.24 \\
$\quad$ Rarely & $11(36.7)$ & $3(10.0)$ & \\
$\quad$ Sometimes & $11(36.7)$ & $16(53.3)$ & \\
$\quad$ Often & $3(10.0)$ & $7(23.3)$ & \\
$\quad$ Very often & $4(13.3)$ & $3(10.0)$ & \\
\hline
\end{tabular}

load," followed by "balancing personal and professional life," and "dealing with death/suffering of patients" were the main stressors.

Within the studied groups, there was no significant difference in stress levels between males and females. Similarly, in the NCCTG, Shanafelt et al. [29] observed no significant differences in job stress; however, an increased rating of a lower degree of overall well-being among female medical oncologists was observed $(P=$ 0.02). Likewise, Buddeberg et al. [30] did not identify gender-specific discrepancies in their prospective longitudinal study focused on work stress, health, and life satisfaction in Switzerland among young doctors.

In contrast, Hipp et al. [24] found significant genderspecific differences. Female physicians rated a higher total stress score. An explanation for this difference might be caused by the fact that women reaching the step of medical specialization or functional position have to face, besides their job stress, they are mothers.

In the meta-analysis by Purvanova and Muros [20], they found gender-specific features among work-related burnout cases. They identified emotional exhaustion and depersonalization, and significant differences between the described effects in the USA and European Union relying on conservative or progressive labor politics.

High stress levels in an unsupportive environment not only reduce the quality of life of the stressed individual themselves but also has the potential to reduce the quality of patient care [31, 32] as well as increasing job turnover rates, absenteeism, and lowering worker morale 
[31, 33]. Organizations need to either address these high stress levels and/or provide their employees with the support and tools to effectively manage their stress in order to reduce burnout and enhance work engagement $[34,35]$. European studies suggest that organizationally based strategies to reduce burnout should focus on job redesign, flexible work schedules, and goal setting. In addition, job satisfaction and engagement could be increased through participative management, increasing social support and team building [34, 36-38].

\section{Conclusion}

It is considered that the results obtained can constitute an important contribution to the understanding of the factors of occupational stress in oncologists and other physicians for the development of actions that prevent adverse reactions in the professionals' health and wellbeing, and which consequently promote the quality of the services provided to the patient. In this preventive context, it is essential to implement strategies which aim to: (1) improve the organization of the work and the distribution of the roles, such as abilities, personal and collective resources may be respected and used effectively; (2) improve the communication channels (improvement of information exchange between teams), making such communication more effective; (3) make professional development and growth possible; (4) set up continuing training programs (training at work or promotion of training courses giving qualifications in generic or specific skills); and (5) develop programs for stress support and prevention (discussion groups and support/psychosocial support groups to help monitor stress and resolve problematic situations).

\section{Limitation of the study}

The cross-sectional study together with number of participants may not be enough to generalize the current results to the population-based cases. It should be noted, however, that the sample used included all the oncologists in our hospital.

\section{Acknowledgements}

The authors thank subjects for their participation and cooperation.

\section{Authors' contributions}

Suzy, Suzan, and Shiamaa analyzed and interpreted the patient data regarding the clinical data and psychometric tools and Mohamed was a major contributor in writing the manuscript. All authors read and approved the final manuscript.

\section{Funding}

This study did not receive any fund.

Availability of data and materials Not applicable

\section{Ethics approval and consent to participate}

This study was approved by the Ethics Committee of Faculty of Medicine, Menoufia University. Written informed consents were obtained from subjects of the study. The number of approval is not applicable.

Consent for publication

Not applicable.

\section{Competing interests}

"The authors declare that they have no competing interests" in this section.

\section{Author details}

'Department of Psychiatry, Faculty of medicine, Fayoum University, PO Box: 63514, Fayoum, Egypt. ${ }^{2}$ Department of Clinical Oncology, Faculty of Medicine, Menoufia University, ShebinElkom, Egypt. ${ }^{3}$ Department of Public Health and Community Medicine, Faculty of Medicine, Menoufia University, ShebinElkom, Egypt.

Received: 25 February 2020 Accepted: 10 March 2020

Published online: 01 April 2020

\section{References}

1. Leka, S., Griffiths, A., Cox, T. and World Health Organization, (2003). Work organisation and stress: systematic problem approaches for employers, managers and trade union representatives. World Health Organization.

2. Noblet A, Lamontagne AD (2006) The role of workplace health promotion in addressing job stress. Health Promot Int 21(4):346-353

3. Karasek R (1979) Job demands, job decision latitude, and mental strain: implication for job redesign. Adm Sci Q 24:285-308

4. Siegrist J, Peter R, Junge A, Cremer P, Seidel D (1990) Low status control, high effort at work and ischemic heart disease: prospective evidence from blue-collar men. SocSci Med 31(10):1127-1134

5. Nieuwenhuijsen K, Bruinvels D, Frings-Dresen M (2010) Psychosocial work environment and stress-related disorders, a systematic review. Occup Med 60(4):277-286

6. Sehlen S, Vordermark D, Schäfer C et al (2009) Job stress and job satisfaction of physicians, radiographers, nurses and physicists working in radiotherapy: a multicenter analysis by the DEGRO Quality of Life Work Group. Radiat Oncol 4:6

7. Hedlund, S. and Clark, E., (2001). End of life issues. Social work in oncology: supporting survivors, families, and caregivers, pp. 299-316.

8. Travado L, Grassi L, Gil F, Ventura C, Martins C et al (2005) Physician-patient communication among Southern European cancer physicians: the influence of psychosocial orientation and burnout. Psycho-Oncology 14:661-670

9. The Work Place Stress Scale (WSS) (2001). The Marlin Company, North Haven, Connecticut and The American Institute of Stress, Yonkers, New York.

10. Burman R, Campbell M, Makin W, Todd C (2007) Occupational stress in palliative medicine, medical oncology and clinical oncology specialist registrars. Clinical Medicine 7(3):235-242

11. Blenkin H, Deary I, Sadler A et al (1995) Stress in NHS consultants. Br Med J 310:534

12. Ramirez A, Graham J, Richards M et al (1996) Mental health of hospital consultants: the effects of stress and satisfaction at work. Lancet 347: 724-728

13. Firth-Cozens J (2003) Doctors, their wellbeing, and their stress it's time to be proactive about stress-and prevent it. BMJ. 326:670

14. Schindler BA, Novack DH, Cohen DG, Yager J, Wang D, Shaheen NJ, Guze P, Wilkerson $L$ et al (2006) The impact of the changing health care environment on the health and well-being of faculty at four medical schools. Acad Med 81:27-34

15. Ahsan N, Abdullah Z, Fie DYG, Alam SS (2009) A study of job stress on job satisfaction among university staff in Malaysia: empirical study. Eur J Soc Sci 8(1):121-131

16. Ghazali SSA, Shah IA, Zaidi SAA, Tahir MH (2007) Job satisfaction among doctors working at teaching hospital of Bahawalpur, Pakistan. Journal of Ayub Medical College Abbottabad 19(3):42-45

17. Archibong IA, Bassey AO, Effiom DO (2010) Occupational stress sources among university academic staff. European Journal of Educational Studies 2(3):217-225 
18. Glasberg J, Horiuti L, Novais MAB et al (2007) Prevalence of the burnout syndrome among Brazilian medical oncologists. Rev Assoc Med Bras 53: 85-89

19. Kuerer HM, Eberlein TJ, Pollock RE et al (2007) Career satisfaction, practice patterns and burnout among surgical oncologists: report on the quality of life of members of the Society of Surgical Oncology. Ann Surg Oncol 14: 3043-3053

20. Purvanova RK, Muros JP (2010) Gender differences in burnout: a metaanalysis. J Vocat Behav 77(2):168-185

21. Blanchard P, Truchot D, Albiges-Sauvin L et al (2010) Prevalence and causes of burnout amongst oncology residents: a comprehensive nationwide cross-sectional study. Eur J Cancer 46:2708-2715

22. Bragard I, Dupuis G, Razavi D et al (2011) Quality of work life in doctors working with cancer patients. Occup Med (Lond) 62:34-40

23. Ramondetta LM, Urbauer D, Brown AJ et al (2011) Work related stress among gynecologic oncologists. Gynecol Oncol 123:365-369

24. Hipp M, Pilz L, Al-Batran SE, Hautmann MG, Hofheinz R (2015) Workload and quality of life of medical doctors in the field of oncology in Germany - a survey of the working group quality of life of the AIO for the study group of internal oncology. Oncol Res Treat 38:154-159

25. Akerstedt T (1990) Psychological and psychophysiological effects of shift work. Scand J Work Environ Health 16:67-73

26. Isikhan V, Comez T, Danis MZ (2004) Job stress and coping strategies in health care professionals working with cancer patients. Eur J Oncol Nurs 8(3):234-244

27. Ramirez AJ, Graham J, Richards MA et al (1995) Burnout and psychiatric disorder among cancer clinicians. Br J Cancer 71:1263-1269

28. Camps C, Escobar Y, Esteban E et al (2009) Professional burnout among Spanish medical oncologists. Clin Transl Oncol 11:86-90

29. Shanafelt TD, Novotny P, Johnson ME et al (2005) The well-being and personal wellness promotion strategies of medical oncologists in the North Central Cancer Treatment Group. Oncology 68:23-32

30. Buddeberg-Fischer B, Stamm M, Buddeberg C et al (2008) Work stress, health and satisfaction of life in young doctors: results of a longitudinal study in Switzerland. Dtsch Med Wochenschr 133:2441-2447

31. Akroyd D, Caison A, Adams RD (2002) Burnout in radiation therapists: the predictive value of selected stressors. Int J Radiat Oncol Biol Phys 52:816-821

32. Poulsen M, Poulsen A, Khan A, Poulsen E, Khan S (2011) Work engagement in cancer workers in Queensland: the flip side of burnout. Journal of Medical Imaging and Radiation Oncology 55:425-432

33. Probst H, Griffiths S, Adams R, Hill C (2012) Burnout in therapy radiographers in the UK. Br J Radiol 85:e760-e765

34. Schaufeli WB, Bakker AB (2004) Job demands, job resources, and their relationship with burnout and engagement: a multi-sample study. Journal of Organizational Behavior: The International Journal of Industrial, Occupational and Organizational Psychology and Behavior 25(3):293-315

35. Clement S, Jarrett M, Henderson C, Thornicroft G (2010) Messages to use in population-level campaigns to reduce mental health-related stigma: consensus development study. Epidemiology and Psychiatric Sciences 19(1): 72-79

36. Xanthopoulou D, Bakker AB, Dollard MF, Demerouti E, Schaufeli WB, Taris TW, Schreurs PJ (2007) When do job demands particularly predict burnout? J Manag Psychol

37. Schaufeli WB, Bakker AB, Van Rhenen W (2009) How changes in job demands and resources predict burnout, work engagement, and sickness absenteeism. Journal of Organizational Behavior: The International Journal of Industrial, Occupational and Organizational Psychology and Behavior 30(7):893-917

38. Van Emmerik IH, Bakker AB, Euwema MC (2009) Explaining employees' evaluations of organizational change with the job-demands resources model. Career Dev Int

\section{Publisher's Note}

Springer Nature remains neutral with regard to jurisdictional claims in published maps and institutional affiliations.

\section{Submit your manuscript to a SpringerOpen ${ }^{\circ}$ journal and benefit from:}

- Convenient online submission

- Rigorous peer review

- Open access: articles freely available online

- High visibility within the field

- Retaining the copyright to your article

Submit your next manuscript at $\boldsymbol{\nabla}$ springeropen.com 